\title{
Emotional Impulsiveness: A Link to Violent Criminality in the Personality Disordered?
}

Howard RC*

Rampton High Secure Hospital, UK

*Corresponding author: Richard C Howard, Rampton High Secure Hospital, UK, E-

mail: Richard.Howard@nottingham.ac.uk

\section{Mini Review}

Volume 3 Issue 2

Received Date: February 10, 2018

Published Date: March 05, 2018

\section{Mini Review}

It is well-established and beyond dispute that some individuals diagnosed with personality disorders are predisposed to offend violently [1]. But what is it about personality disorder (PD) that predisposes such individuals to violence? Personality disorders are not alone in predisposing to violence, which has been found to be linked to a range of other mental disorders, including schizophrenia (odds ratio 7.4) [2], bipolar disorder (odds ratio 5.8) [3], and depression (odds ratio 3.0) [4]. In reviewing the functional link between PD and violence, Duggan and Howard [5] gave the example of a patient who meets criteria for both narcissistic and paranoid PDs, has multiple (DSM-IV) Axis I conditions including substance use and post-traumatic stress disorder (PTSD) and is prone to violence. They ask: "Does one give precedence to a blow to the individual's selfesteem (narcissism), or to a suspiciousness of the motives of others (paranoid traits), his or her substance abuse or the activation of PTSD symptoms in explaining his or her violent behaviour?" (p.25). In other words, which condition has causal primacy in determining the links between mental disorder and violent behavior?

Posing the question in this way presupposes that the link between psychiatric disorder and violence operates at the level of individual diagnostic categories. However, the fact that a predisposition to violence transcends particular categories of psychiatric illness should alert us to the possibility that we need to look at the link between psychiatric disorder and violence from a different perspective. The recently proposed Hierarchical Taxonomy of Psychopathology (HiTOP: [6]) model offers such an alternative perspective. In this model, symptoms/signs (level 1) are nested within maladaptive traits (level 2) which in turn are nested within syndromes/disorders (level 3). At a higher level of the hierarchy (level 5) are situated broad spectra, namely internalizing pathology, externalizing pathology (comprising disinhibited and antagonistic externalizing), thought disorder (i.e., psychosis spectrum disorders), and detachment (i.e., pathological introversion). At the highest level of the hierarchy are super-spectra, higher-order dimensions of psychopathology. One such superspectrum is overall psychopathology (p) [7]. It has been proposed that higher $\mathrm{p}$ scores are associated with more life impairment, greater familiality, worse developmental histories, and more compromised early-life brain function [7]. Overt acts of aggression and violence are located at the bottom level of this hierarchy (signs and symptoms), but a predisposition to violence can be seen as related to all higher levels of the hierarchy. Thus violence is associated, at level 2, with maladaptive traits associated, in the Five Factor Model (FFM) of personality, with low Conscientiousness, low Agreeableness and high Neuroticism [8]. Of general traits included in the FFM, Antagonism, which includes traits such as suspiciousness, combativeness, deceptiveness, lack of empathy and arrogance, is the most strongly related to interpersonal violence in civil psychiatric patients, with Neuroticism also related but to a lesser degree [9]. At level 3, violence is associated with a wide variety of psychiatric syndromes, most notably, in the context of personality disorders, with co-occurring antisocial and borderline personality disorders [10]. At the level of spectra (level 5), violence can be seen as associated with disinhibited and antagonistic externalizing, and with aspects of internalizing (e.g. distress). 


\section{Psychology \& Psychological Research International Journal}

At the highest level of the HiTOP hierarchy, higherorder dimensions of psychopathology or 'super-spectra', violence is related to overall level of psychopathology (p) [7]. An important putative contributor to $\mathrm{p}$ is emotional impulsiveness, defined as the tendency to act rashly, precipitately, and without regard for negative consequences under the pressure of emotional arousal. The current author [11] has reviewed research findings suggesting that emotional impulsiveness in adulthood has its origins in childhood temperament and, manifested in the propensity to experience and express anger, runs continuously through the developmental fabric of severe personality disorder, from early through late childhood, into adolescence and adulthood. Evidence is further reviewed suggesting that emotional impulsiveness is associated with severe personality disorder, and accounts, at least in part, for the propensity to violence shown by those with severe personality disorder. Other individual factors contributing to $\mathrm{p}$, and hence to violence risk, are traits associated with psychopathy and delusional thinking [12,13]. It is important to note, however, that these characteristics of the individual's personality operate in concert with contextual factors, such as alcohol use and interpersonal stress, to increase his/her risk of violence. Thus a violent outcome is never entirely predetermined by an individual's personality, but is dependent on the context (e.g. a private vs. public space) in which the individual finds him/herself. Even the most emotionally impulsive persons would, if they avoided contexts in which they would be at risk of committing a violent act, be immune to the commission of such an act.

\section{References}

1. McMurran M, Howard RC (2009) Personality, personality disorder and violence. Wiley, Chichester, pp: 340 .

2. Fazel S, Wolf A, Palm C, Lichtenstein P (2014) Violent crime, suicide, and premature mortality in patients with schizophrenia and related disorders: a 38-year total population study in Sweden. Lancet Psychiatry 1(1): 44-54.

3. Fazel S, Lichtenstein P, Frisell T, Grann M, Goodwin G, et al. (2010) Bipolar disorder and violent crime: time at risk reanalysis. Arch Gen Psychiatry (12): 13251326.
4. Fazel S, Wolf A, Chang Z, Larsson H, Goodwin GM, et al. (2015) Depression and violence: a Swedish total population study. Lancet Psychiatry 2(3): 224-232.

5. Duggan C, Howard RC (2009) The 'functional link' between personality disorder and violence: a critical appraisal. In: McMurran M, Howard RC, (eds.), Personality, personality disorder and violence, Wiley, Chichester, pp:19-37.

6. Kotov R, Krueger RF, Watson D, Achenbach TM, Althoff RR, et al. (2017). The hierarchical taxonomy of psychopathology (HiTOP): a dimensional alternative to traditional nosologies. Journal of Abnormal Psychology 126(4): 454-477.

7. Caspi A, Houts RM, Belsky DW, Harrington H, Israel S, et al. (2014) The $p$ factor: one general psychopathology factor in the structure of psychiatric disorders. Clin Psychol Sci 2(2): 119-137.

8. McCrae RR, Costa PT (1987) Validation of the fivefactor model of personality across instruments and observers. Journal of Personality and Social Psychology 52(1): 81-90.

9. Skeem JL, Miller JD, Mulvey ET, Tiemann J, Monahan J (2005) Using a five-factor lens to explore the relation between personality traits and violence in psychiatric patients. Journal of Consulting and Clinical Psychology 73(3): 454-465.

10. Howard RC (2017) Co-Occurring Antisocial and Borderline Personality Disorders: A Single Syndrome? Ann Psychiatry Ment Health 5(6): 1120.

11. Howard RC. Emotional impulsiveness: A higher-order dimension of psychopathology that contributes to criminality. In: Understanding Impulsive Behavior: Assessment, Influences and Gender Differences (Nova Scientific Publications, in press).

12. Howard RC (2015) Personality disorders and violence: what is the link? Borderline Personality Disorder and Emotion Dysregulation 2: 12.

13. Howard RC (2017) Psychopathy, Impulsiveness and Violence: How are they linked? J Behav 2(1): 1004. 